\title{
STUDY OF UNIVERSITY TEACHERS 'ATTITUDES TO APPLY TO RESEARCH TEACHING
}

\author{
Rumyana Neminska ${ }^{1 *}$ \\ ${ }^{* 1}$ Faculty of Pedagogy, Thrakya University, Bulgaria, Faculty of Education, Thracian University
}

*Corresponding Author: -

Email ID: neminska@abv.bg

\begin{abstract}
: -
The article traces trends in the development of research teaching in an academic setting. The problem is addressed in two areas: scientific-theoretical and reflexive-empirical. The scientific and theoretical part presents the relation between the quality of training and research training. The reflexive-empirical section presents the results of a study conducted among academic staff at some Bulgarian universities. The survey used to conduct the survey examines areas such as reflection and self-reflection in teaching. Theoretically justified conclusions are presented.

The current trends in the research training of students at Bulgarian universities are outlined.
\end{abstract}

Keywords: research training, methodology, higher education

\section{(c) $\$(1)$}




\section{Research teaching}

The European vision for improving the quality of education in higher education emphasizes that one of the important conditions is a change in teaching methods. Greater access to higher education and cultural diversity is leading to a change in learning and teaching approaches. Leads to flexible training models. (Towards a European Education Education Area, 2025).

In this article, the quality of training is addressed in terms of reflective methodology. Assuming that it is based on methodological pluralism and interdisciplinarity. Recognizes the personality of the individual and the outstanding or hidden assets of the students. Reflective teaching can also be fleshed out as "learning through development for all" (Burnham and Anderson, 2002). It refers to the use of knowledge acquired through exploration in various activities and the development of one's own body of knowledge. In this training, students are encouraged to deepen their research on the pedagogical phenomenon, to work on innovative tasks designed by the teacher. In the process of research teaching, each student follows his or her own path to build and organize knowledge. He is learning how to learn, not how to store information. This learning process is commented on by Georgieva, D. as building a "personal professional philosophy" (Georgieva, D. 2019).

The purpose of research teaching is to provide a learning environment for students to explore various aspects of pedagogical problems. This simulated learning environment has not only a physical characteristic but also a deeply motivational and psychological aspect.

\section{Methodology and technology of research training}

The research methodology reveals a common approach to "learning and explaining learning processes and phenomena" (Petrov, P., 2016). The basic approach in the current methodology is research. In the research methodology the leading role is played by the choice of the teacher - the methodological toolkit and the research orientation. Therefore, the methodological culture of the teacher and his / her methodological reflection skills play an important role. Important is his ability to analyze his own scientific activity, scientific substantiation, critical understanding and creative application of certain concepts, forms and methods of knowledge. The definition of this phenomenon can be called - "methodological integration complex". Doncheva, J. understands the methodological complex as "a whole process of interaction ... in which education from static, from hierarchical becomes process, in interaction, in multiplication, in permanent breaking of forms" (Doncheva, J., 2016) . A team of scientists (Lazarev, Stavrinov, 2006) determines that the methodological integration complex reflects the teacher's professional readiness to manage the research learning process. The application of the methodological integration complex develops the reflective technology of research training. Petrov, P. views pedagogical technology as "a concept that integrates all theoretical and applied fields" (Petrov, P., 2016). Reflective technology is a combination of research methods. It is activity-oriented to the training subjects. Allows in the learning process to reflect on the learning motivation, to correct elements of the learning process.

\section{Research methodology (Empirical research)}

The main components of the methodology of research teaching are: methodological integration complex and reflective technology.

The purpose of empirical research is to investigate the application of two components of the teaching process of university professors.

Tasks of empirical research:

1. Tracking the students 'reflection on the students' cognitive activity.

2. Tracking teachers' self-reflection on their own experience of teaching and evaluating students.

3. Outline trends in the development of research teaching in an academic setting.

The survey used to conduct the study (Appendix 1) consists of three parts: passport, reflexive, self-reflective. In the first part the respondents enter the names, the university and the discipline in which they teach. The second part of the questionnaire reflects the students' reflective activity. There are three main statements. The third part of the questionnaire focuses on teaching selfreflection. There are three main statements. These statements are components of research training.

\section{Empirical data}

\section{FIRST PART}

The empirical study included 79 university professors from Bulgarian universities. The data from the passport are presented by lecturers from: the University of „St. Kliment Ohridski“ - Sofia;

„St. St. Cyril and Methodius“- Veliko Tarnovo, Military University - Veliko Turnovo, „Angel Kanchev“ University Rousse; „Konstantin Preslavski“ University - Shoumen, Pedagogical Faculty of Thrakya University - Stara Zagora.

\section{SECOND PART}

\section{FIRST QUESTION:}

Thesis First Two (2.1. A): "Do you think that the students you work with are actively participate in the learning process?" The teachers' answers form the following empirical data:

Answer: "To a small degree" - noted by 38\% (30 of the teachers); Answer: „Yes“- noted by 32\% (25 teachers); Answer: „No“ - noted by $30 \%$ (24 teachers). 
Thesis Second (2.1.B): "Do you think that the students you work with are interested in the assigned learning tasks". Teachers' responses form the following empirical data:

Answer: „Yes“- 52\% (41 teachers); Answer: "To a small degree" - 48\% (38 teachers).

Thesis Third (2.1.C): "Do you think that the students you work with are interested in the problems being studied?" Teachers' responses form the following empirical data:

Answer: „Yes“- 43\% (34 teachers); Answer: „No“ - 30\% (24 teachers); Answer: "To a small degree" - $27 \%$ (21 teachers).

\section{SECOND QUESTION:}

Thesis first (2.2. A): "Do you think that the students you work with prefer to learn theoretical knowledge and concepts" form the following empirical data:

Answer: ,Yes“" - 90\% (71 teachers); Answer "To a small degree" - 10\% (8 teachers).

Thesis Two (2.2. B):"Do you think that the students you work with prefer to comment and reflect on problems encountered during the lecture course?"

Answer „Yes“ - 90\% (71 teachers); Answer "To a small degree" - 10\% (8 teachers)

Thesis Third (2.2. C): "Do you think that the students you work with prefer to critically reflect on and accept different theories?"

Answer „Yes“ - 80\%; (63 teachers); Answer „To a small degree“ - 20\% (16 teachers).

Thesis Four (2.2. D): "Do you think the students you work with prefer to work on study projects, case studies and abstracts?"

Answer „Yes“, 80\%; (63 teachers ); Answer „To a small extent““ - 20\% (16 teachers).

\section{THIRD PART}

The first statement (3.1.), " Testing and evaluation of the acquired knowledge and skills in your discipline is done through...".

The answers of the interviewed lecturers form the following empirical data:

- the combination of A) test and B) exam - 37\% (29 teachers);

- the combination of "B) exam and C) Study project defense or case study" - 59\% (47 teachers);

- $\quad$ answer "D) Reflective Technology Test" - 4\% (3 teachers).

The second statement in Part Three (3.2.), "Thematic Priority in Your Teaching is ...". The following analysis data are generated:

- the combination of A) "Basic Theories and Concepts" and D) "Problem Solving Methods and Techniques" - 48\%. (38 teachers);

- the combination of A) "Basic Theories and Concepts" and B) "Discussions in the scientific field in which you work" - 44\% (35 teachers);

- the combination of B) "Discussions in the scientific field in which you work" and C) "Your research" is noted by $8 \%$ (6 teachers).

\section{Analysis of empirical data}

Aggregated data and results provide a multifaceted picture for research. Therefore, the analysis seeks to identify a trend - do university professors (within the boundaries of research) use research training as a rationale for higher quality. In the survey, the concept of research training is operationalized through the presented thesis answers.

The "teaching picture" of students' attitudes toward academic learning in pedagogical profiles outlines a recurring trend in learning activities. The comparative analysis shows a sustained interest in pedagogical training - $70 \%$ show cognitive activity in the learning process $(38 \%+32 \%$, which includes the low grade).

This percentage also appears when taking into account the interest in the studied issues $-70 \%(43 \%+27 \%$ which includes the low degree). The sustained result of interest and activity correlates with the completion of the learning tasks. There is no negative result in this activity criteria. However, high activity and interest are not reported, summarizing data from low student activity.

The student learning-cognitive activity finds its grounds in the outlined interest and preferences summarized in the following statements. Teachers have indicated that $90 \%$ of students prefer practical, targeted knowledge; the same values (in percentages) students engage with interest in a project activity and work with case studies.

\section{Comparative analysis of teaching reflection outlines two trends:}

- Sustainable positive tendency of cognitive activity and interest, the values of which include low levels of activity and interest;

- Sustainable negative trend of student activity and interest - 30\%. Comparative correlations can summarize that $30 \%$ of students show low levels of activity and interest and 30\% of students are not active and are not interested in learning problems. Comparative analysis of the components of interest also outlines a stable part - $20 \%$ of students who do not show any interest in learning problems. Benchmarking data leads to a relational approach to teaching technology. Reflection to a higher stage: self-reflection. 
Against the background of the outlined educational-cognitive activity and interest of the students, a comparative analysis of the teacher's self-reflection in the educational process is made.

The first component is related to evaluation. The most preferred format for assessing students' knowledge and skills is the combination of B) Exam and C) Protecting a study project or solving a case study - 59\% (47 teachers). They are followed by $37 \%$ (29 teachers) - the combination of A) test and B) Exam.

Interest in the study is the positive fact that teachers use a combination of forms (even just two) to evaluate students' knowledge and skills. The assessment combinations used, however, fail to motivate that stable proportion of students, indicated as inactive and to a small extent. In this sense, the comparative results in the area of teaching methodology are also interesting.

The analysis seeks out those methodological combinations that most positively influence students' educational and cognitive activity.

It outlines that there is a direct relationship between empirical data:

$30 \%$ (24 teachers) of negative activity and 30\% of activity "to a small degree" with the choice of combination for teaching - A) "Basic theories and concepts" and D) "Methods and techniques for solving problems" - 48\% (38 teachers ).

The fact that $90 \%$ (71 teachers) prefer to acquire knowledge through practical activities justifies a serious methodological and technological mismatch.

Another more positive relation can be found between 38\% (30 teachers) actively involved in the learning process, $43 \%$ (34 teachers) who study the learning process with interest and the combination of teaching from A) "Basic Theories and Concepts" and B ) "Discussions in the scientific field in which you work" - 44\% (35 teachers) of the teachers.

In the empirical study, low values of teachers using reflective technology are outlined - 4\% (3 pieces). Reflection on one's own research is a component of the reflective teaching technology of teaching. It is estimated that a very small proportion of teachers $-8 \%$ (6 teachers) include their research in the teaching process. It can be clarified here that the reflexive research environment of teaching is taxonomically situated in the cognitive field of analysis, synthesis, assessment, application. The goal is for students to develop critical pedagogical thinking. The goal is also for every student from a passive user of knowledge to discover themselves as actively creating knowledge. The analysis of the empirical data (within the boundaries of the study) shows that the academic audience debate on the scientific product of the teacher is very low. And according to the theoretical assumptions of research training, this is one of the leading factors that develops teacher's self-reflection and student's reflection. This can greatly influence students' cognitive activity, interest and motivation.

\section{Conclusions and generalizations}

The survey achieved operationalization of research training. Two main characteristics of it are outlined: reflection and self-reflection. Knowing that activity-oriented and subject-subject approaches are leading in research training:

reflection focused on the examination of students' educational and cognitive activity in

different learning activities;

self-reflection focused on the examination of one's own teaching activity through various

activities (assessment and teaching).

By tracing the correlations between learning reflection and teaching self-reflection, it can be summarized that low cognitive activity is caused by non-flexible teaching and assessment methods. Following the empirical study, it turns out that the 79 university professors surveyed applied research training to a very small extent in academic audiences. They prefer to apply static (subjectobject) forms: theoretical materials, tests. Interactive forms are also applied, which in themselves are positive factors for the development of activity and interest. But these interactive forms are not included in integration methodological complexes. In this way, they remain outside the technology of research training.

The aim of the study was to identify trends in the development of research training among the 79 university professors surveyed. It turns out that very few of them - $4 \%$ and $8 \%$ apply components of this type of training. Which in turn opens a new methodological and technological path in university education.

\section{REFERENCES:}

[1].Bell, Urhahne, Schanze, Ploetzner, (2010) Collaborative inquiry: Learning: Models, Tools, and Challenges, International Journal of Science Education Vol. 32, Number 3, ISSN 0950-0693

[2].Brookfield, S. (2000). The concept of critical reflective practice. In A. L. Wilson \& E. R. Hayes (Eds.), Handbook of adult and continuing education (pp. 33-49). San Francisco, CA: Jossey-Bass.

[3].Burnham and Anderson (2002) Model Selection and Multimodel Inference: A Practical Information - Theoretic approach, Wildlife Management Member 67 (3) DOI: 10,1007/b97636)

[4].Georgieva D. (2019) Alternative Communication in Children with Hearing Impairments (Visual Acceptance of Speech), Thracian University Publishing House, p. 10.

[5].Doncheva, J., (2016) Reflective characteristics of the interactive educational environment in elementary school, In: Annual University Scientific Conference of Vasil Levski National Military University, pp. 94-101, ISBN 2367-7481

[6].European Higher Education Area and Bologna Process - http://www.ehea.info/

[7].Kozhuharova, G. (2015) The philosophical and methodological essence of the concept approach. Pedagogical Forum, 2, DOI: 10.15547 / PF.2015.015.

[8].Lazarev, V. S., Stavrinov N. N. (2006) Criteria and levels of future teacher's readiness for research activities, Pedagogics, pp. 51-59

[9].Petrov, P., (2016) Contemporary didactics, Vanguard Prima Sofia ISBN 978-619160-688-7

Vol. 6 No. 1 (2020) 
[10]. Towards a European Education Education Area, 2025 https://ec.europa.eu/commission/news/towards-europeaneducation-area-2025-2017-nov14 en

\begin{tabular}{|c|c|c|c|c|c|}
\hline \multicolumn{6}{|c|}{ I. PASSPORT PART } \\
\hline 1.1. & University: & & & & \\
\hline 1.2 . & Faculty: & & & & \\
\hline 1.3. & The courge in which you teach: & & & & \\
\hline 1.4 . & Academic position: & & & & \\
\hline II. & \multicolumn{5}{|l|}{$\begin{array}{l}\text { TEACHING REFLECTION: } \\
\text { / Mark the correct answers for you! / }\end{array}$} \\
\hline 2.1 . & Do you think the students you work with: & YES & No & $\begin{array}{l}\text { A SMALL } \\
\text { DEGREE }\end{array}$ & OTHERS \\
\hline $\mathrm{A} /$ & $\begin{array}{l}\text { actively participate in the learning process } \\
\text { (lectures and exercises)? }\end{array}$ & & & & \\
\hline $\mathrm{B} /$ & $\begin{array}{l}\text { fulfill with interest the assigned learning } \\
\text { tasks? }\end{array}$ & & & & \\
\hline $\mathrm{C} /$ & are interested in the problems studied? & & & & \\
\hline 2.2 & $\begin{array}{l}\text { Do you think the students you work with } \\
\text { prefer to: }\end{array}$ & & & & \\
\hline $\mathrm{A} /$ & learn theoretical knowledge and concepts? & & & & \\
\hline $\mathrm{B} /$ & $\begin{array}{l}\text { to comment and reflect on problems } \\
\text { encountered during the lecture course? }\end{array}$ & & & & \\
\hline $\mathrm{Cl}$ & $\begin{array}{l}\text { critically reflect and accept different } \\
\text { theories? }\end{array}$ & & & & \\
\hline $\mathrm{D}^{\prime}$ & $\begin{array}{l}\text { work on study projects, case studies and } \\
\text { abstracts? }\end{array}$ & & & & \\
\hline III. & $\begin{array}{l}\text { TEACHING SELF-REFLECTION } \\
\text { Note the truth of your opinion!/ }\end{array}$ & & & & \\
\hline 3.1 . & $\begin{array}{l}\text { Testing and evaluation of the acquired } \\
\text { knowledge and skills in your discipline is } \\
\text { done through : }\end{array}$ & YES & NO & $\begin{array}{l}\text { IN A SMALL } \\
\text { EXTENT }\end{array}$ & OTHERS \\
\hline $\mathrm{A} /$ & Test & & & & \\
\hline $\mathrm{B} /$ & Exam (oral or written) & & & & \\
\hline $\mathrm{Cl}$ & Protecting a study project or solving a case & & & & \\
\hline $\mathrm{D} /$ & Reflective technology & & & & \\
\hline 3.2 . & A thematic priority in your teaching is: & & & & \\
\hline$A /$ & Basic theories and concepts & & & & \\
\hline$B /$ & $\begin{array}{l}\text { Discussions in the scientific field in which } \\
\text { you work }\end{array}$ & & & & \\
\hline $\mathrm{C} /$ & Your research & & & & \\
\hline D/ & Problem solving methods and techniques & & & & \\
\hline
\end{tabular}

